\title{
The Spatial Representation of Power in Children
}

Lifeng $\mathrm{Lu}^{\mathrm{a}}$, Thomas W. Schubert ${ }^{\mathrm{b}}$, Lei $\mathbf{Z h \mathbf { u } ^ { \mathrm { a } }}{ }^{\mathrm{CA}}$

aDepartment of Psychology, Fudan University, Handan Road 220, Shanghai, SH 200433, China

${ }^{\mathrm{b}}$ Department of Psychology, University of Oslo, P.O box 1094, Blindern 0317, Oslo, Norway

Unedited final draft, Published as

Lu, L., Schubert, T. W., \& Zhu, L. (2017). The spatial representation of power in children. Cognitive Processing. doi:10.1007/s10339-017-0814-9. Published online May 2017.

${ }^{\mathrm{CA} C o r r e s p o n d i n g ~ A u t h o r ~ a n d ~ A d d r e s s: ~ j u d y 1981 \_81 @ ~ h o t m a i l . c o m ~}$

Address correspondence to:

Lei Zhu, Ph.D.

Department of Psychology, Fudan University

Handan Road 220

Shanghai, SH 200433

R. P. China

E-mail: judy1981_81@hotmail.com

Phone: 086-021-66517885

Fax: 086-021-65643490 


\begin{abstract}
Previous evidence demonstrates that power is mentally represented as vertical space by adults. However, little is known about how power is mentally represented in children. The current research examines such representations. The influence of vertical information (motor cues) was tested in both an explicit power evaluation task (judge whether labels refer to powerless or powerful groups) and an incidental task (judge whether labels refer to people or animals). The results showed that when power was explicitly evaluated, vertical motor responses interfered with responding in children and adults, i.e., they responded to words representing powerful groups faster with the up than the down cursor key (and vice versa for powerless groups). However, this interference effect disappeared in the incidental task in children. The findings suggest that children have developed a spatial representation of power before they have been taught power-space associations formally, but that they do not judge power spontaneously.
\end{abstract}

Keywords: children; power; space; representation 


\section{The Spatial Representation of Power in Children}

An essential question that has received much attention within the domain of cognitive psychology is how abstract concepts are mentally represented. In the social domain, one of these abstract concepts is power. Systematic research over the last decade has demonstrated representation of power as magnitude, specifically spatial magnitude (Chiao et al., 2009; Chiao, 2010; Giessner \& Schubert, 2007; Jiang et al., 2015ab; Mason, Magee, \& Fiske, 2014; Schubert, 2005; Zanolie et al., 2012). However, little is known about how power is mentally represented in children. The current research examines the spatial representation of power in children.

\section{Modal Representations of Power}

In the psychological literature, power has been defined as the ability or capacity to influence others through the control of resources (Galinsky, Gruenfeld, \& Magee, 2003; Keltner, Gruenfeld, \& Anderson, 2003). When we talk about power in our daily life, we often use vertical information in our language. For example, leaders who supervise their employees have "high" status, or are "up" in the hierarchy, whereas the employees are at the "lower" levels of the hierarchy. Simply put, power is often metaphorically understood, presented, and communicated nonverbally as vertical height in physical space: "control is up, lack of control is down" (Lakoff, 1987; Lakoff \& Johnson, 1980). Understanding the spatial representation of power is important because of its broad implications and use in communication in relations ranging from the interpersonal to societal. It concerns mate selection (Meier \& Dionne, 2009) and leadership in organizations (Giessner \& Schubert, 2007). For 
example, Meier and Dionne found that males preferred female pictures which were presented near the bottom of the screen, whereas females preferred male pictures which were presented near the top of the screen, presumably because powerful males and powerless females are seen desirable in the investigated cultural context.

The association of power with space can be understood within the grounded cognition framework (e.g., Barsalou, 1999, 2008; Glenberg, 1997), which argues that conceptual thinking involves perceptual simulation. Cognizing abstract concepts is assumed to reactivate previously stored information from sensory-motor experience to form a simulation of this sensory-motor experience. Applied to the concept of power, this framework leads to the prediction that concurrently presented but irrelevant spatial cues should modulate thinking about powerful and powerless targets, and that effects typical for spatial magnitudes should be observable for power as well. Support for these predictions has been found in past research on adults (Chiao et al., 2009; Chiao, 2010; Giessner \& Schubert, 2007; Jiang et al., 2015ab; Mason, Magee, \& Fiske, 2014; Schubert, 2005; von Hecker, Klauer, \& Sankaran, 2013; Zanolie et al., 2012).

For example, spatial information provided visually affects power judgments in the vertical dimensions. In one experiment, Schubert (2005) presented participants with a series of pairs of group labels (e.g., employer-employee, master-servant), one at the top and the other at the bottom of the screen, and required them to judge which label was powerful. Participants reacted faster when powerful group labels appeared at the top and powerless group labels appeared at the bottom. In the other experiments, 
single words referring to powerful or powerless groups were presented. Participants decided whether the word represented a powerful or powerless group. The stimulus position (either at the top or at the bottom of the computer screen) or response key (up or down cursor keys) was manipulated. Interactions between stimulus position or response key and power were found, i.e. participants responded faster to powerful groups when they appeared at the top of the screen and to powerless groups when they appeared at the bottom of the screen, and they responded faster to powerful groups with the up cursor key and to powerless groups with the down cursor key.

Subsequent work found that such interactions also appeared during tasks without explicit power evaluation: Jiang et al. (2015a) tested whether power is processed incidentally, and affected by spatial cues, when unrelated semantic judgments are made. For this purpose, Jian et al. presented both words denoting people and words denoting animals (e.g., powerful animal: tiger; powerless animal: cat). The task was not an explicit power evaluation, but rather a decision as to whether an animal or a human label was presented. The spatial cue was again whether the response required an up or down cursor key press. Results showed that participants responded faster to words representing powerful groups with the up cursor key and to words representing powerless groups with the down cursor key, suggesting that semantic processing of power words automatically activates the up-down image schema related to power. This is important because when vertical cues are present in nonverbal communication, interaction partners may not always explicitely judge each other's power. Nevertheless, these results indicate that if a status difference is easily accessible, 
vertical cues can facilitate thought where power and space are aligned.

\section{Development of the Space-Power Association}

There are various theoretical accounts for how associations of sensory-motor content and abstract concepts develop. They vary mainly in two regards, namely in the role that language is assumed to play for the acquisition of the associations, and regarding how much evolutionary preparedness is assumed to be present. For the space-power link, the simplest account assumes a learning of the association through experiencing the link of those concepts in daily life. Athletes who are standing on top of a podium are the winners. Leaders' offices are often located at the top floor of company buildings. Rankings of music or books display the best at the top of the list. From a developmental perspective, children know that their taller parents have power over them. Hence, after repeated exposure to these examples, we become accustomed to such relations (Lakoff \& Johnson, 1980; Schwartz et al., 1982; for an overview, see Casasanto, 2014; Suitner \& Schubert, in press). Implicit knowledge acquired through repeated experience is often characterized as procedural or habitual (Dienes \& Perner, 1999; Kirsh, 1991; Squire, 1992; Smith, 1984). It is possible that the link in language emerges through metaphors that equate or explain power in terms of vertical height. Such metaphors could lead to the concurrent activation of spatial content and status information in mental simulations, serving as a further source of the association acquired through learning.

One question is whether these learning processes are directed or prepared in any way. Thomsen and Carey (2013) argued that an evolved core cognitive module 
underlies the association of space and power by representing both as magnitudes. This is in line with findings that effects typical for concrete magnitudes replicate for power as well (Chiao, 2010), and that already preverbal infants expect larger agents to prevail in zero-sum conflicts (Thomsen, Frankenhuis, Ingold-Smith, \& Carey, 2011). Brey and Shutts (2015) observed that 5-year-old preschool children were sensitive to vertical spatial information inherent in postures when judging social power of people: The children were able to determine which of the two adults was "in charge" in the pictures using vertical information from postures such as head up vs. down. Similarly, Charafeddine et al. (2015) found that pre-school children are already familiar with the association of hierarchical positions and physical supremacy, decision-making power, age asymmetry, and resource asymmetry.

In sum, there is evidence that children from an early age interpret spatial cues available from others' bodies to denote hierarchical position and social dominance. However, it is not clear whether or not they do that also for non-bodily, schematized, spatial cues. Also, it is not clear whether children's thinking about social hierarchy spontaneously evokes simulations of spatial sensory-motor information, or only when power processing is explicitely judged. Information about the development of such spontaneous simulations would be informative about the driving force behind the associations and thus the inclusion of space in the representation of power.

One way to test whether children represent power as vertical space is to adopt task-irrelevant vertical information that is not tied to the representation of others' bodies, but rather schematized. If such non-bodily task-irrelevant vertical information 
is congruent with the image schema related to power and power is actually considered, processing will be facilitated.

To our knowledge there are no studies which have used this method to examine the spatial representation of power in children, there is a study for chimpanzees that used it. Dahl and Adachi (2013) required chimpanzee subjects to discriminate face identities of their familiar chimpanzees in a vertical arrangement. That task does not inherently require status processing, but might evoke it. The power hierarchy of the stimuli (familiar chimpanzee faces) was determined by the researchers and chimpanzees' caretakers. Chimpanzees gave faster responses when high-ranked individuals were presented in higher locations and low-ranked individuals in lower locations. It is reasonable to infer that children have also developed such spatial representation of power. ${ }^{1}$

\section{The Current Research}

In the current studies, we investigate whether schematized, non-bodily spatial cues influence power judgments in children around the age of 10, which would imply that they mentally represent power as space. In two studies, we test whether that is the case when explicit power judgments are required (Study 1) or not (Study 2). Jiang et al. (2015a) found significant interaction effects in adults in both cases. We use their

\footnotetext{
${ }^{1}$ As a note of caution, we want to point out that Dahl and Adachi, 2013, did not control for the bodily height of the individual chimpanzees. In the animal world, an animal's power is often determined by its body size. Therefore, it is possible that high-ranked individuals were taller than the low-ranked individuals and subjects were accustomed to looking up at them in their daily lives. Thus, even if identity discrimination did not activate up-down image schema, responses would also be facilitated when the participants looked up at the high-ranked individuals displayed in the higher locations of the test.
} 
data as a benchmark and comparison.

The studies were conducted with Chinese children as participants. We used Chinese group labels (e.g., king, tiger) following the previous study (Jiang et al., 2015a) instead of pictures of familiar individuals to rule out the confounding variable of body height. An explicit power judgment task was used in Experiment 1 and an incidental task in Experiment 2 (following Jiang et al., 2015a) where no explicit power judgment was required. Instead, in Study 2, being presented with labels referring to either people or animals, participants had to decide whether an animal or person was presented.

To induce task-irrelevant vertical information, we manipulated vertical motor responses, which produce a strong influence on power judgments (Schubert, 2005). Up and down motor response (up or down cursor keys) is analogous to vertical movement of an external object (Hommel et al., 2001; Neumann \& Strack, 2000). Compared to vertical location, Schubert (2005) showed vertical motor responses not only affected response latency, but also accuracy of power judgments. Judgments of words representing powerful groups were more accurate with the up key and judgments of words representing powerless groups were more accurate with the down key. Thus, in Schubert (2005) and Jiang et al. (2015a), the error frequencies were also used as performance index. Each word appeared twice, once assigned to the up key and once to the down key. If children do represent power as vertical space, they should respond to words representing powerful groups with faster up than down cursor key presses, and to words representing powerless groups with faster down than 
up cursor key presses.

Considering that previous studies implied an early development of spatial representation of power, we predicted such representation might arise before they have been taught in school. According to surveys of teaching materials, metaphors about the association of power and space (e.g., high official) do not appear in Chinese textbooks before Grade 6 (Wu et al., 2007). Thus, children of Grade 4 were tested. Children younger than Grade 4 might not recognize all the written Chinese words used in the tasks. Last, given that the present study used the same methods as Jiang et al. (2015a), the adults' data from Jiang et al. (2015a) were also included as reference to evaluate the children's performance.

\section{Experiment 1}

In the first study, we tested space-power interference using an explicit power judgment task. The spatial dimension was manipulated by assignment of response keys. We predicted that response key and power would interact under these conditions of explicit power appraisal, i.e. participants would respond faster to words representing powerful groups with the up cursor key, and faster to words representing powerless groups with the down cursor key. For comparison, the adults' data from Jiang et al. (2015a) were also included. We predicted that children at the age we tested have already developed spatial representation of power similar to what is found in adults. Thus, the interaction between power and space should not differ across age groups. 


\section{Method}

\section{Participants}

Twenty-four right-handed volunteers from a primary school in Shanghai (Grade 4) with normal or corrected-to-normal vision (10 males, 10.75 years old $(S D=0.68)$ ) participated in this experiment. The children were tested approximately five months before the end of the school year. Before the experiment, all the participants were asked which hand was their dominant one, i.e., which hand they used to write and hold chopsticks. All the participants reported that they were right-handed. For comparison, data from 24 right-handed adults (18 males, 23.54 years old $(S D=2.81)$ ) already described in our previous study (Jiang et al., 2015a) was included in the analysis.

\section{Materials}

Sixty-four group labels of two kinds (32 people and 32 animals, see Appendix) were used, identical to the ones used by Jiang et al. (2015a). Half of the labels (16 people \& 16 animals) were of powerful roles and animals (e.g., king) and the other half were of powerless roles and animals (e.g., servant). Another five group labels were adopted as practice items and appeared twice in the beginning of each block. Following the method of Schubert (2005), 12 adults (6 males) who were not included in the formal experiment were recruited to rate the power of each word on a 7-point Likert scale, 1 indicating extremely powerless and 7 indicating extremely powerful. The valence of the words was also rated, because valence is also related to vertical space (i.e., positive is up, negative is down, Meier \& Robinson, 2004; Schubert, 2005). 
A $2 \times 2$ ANOVA (power and animal/person kind) on power ratings revealed that the words representing powerful groups were rated to be more powerful than the words representing powerless groups, $F(1,60)=351.18, p<.001$. The power ratings of people were not significantly different from those of animals, $F(1,60)=1.52, p=.22$. The interaction was also significant, $F(1,60)=29.53, p<.001$. Further analyses indicated that the powerful people were rated to be more powerful than the powerless people, $F(1,30)=50.78, p<.001$, and the powerful animals were rated to be more powerful than the powerless animals, $F(1,30)=1137.75, p<.001$. The powerful animals were rated to be more powerful than the powerful people, $F(1,30)=6.31, p$ $<.05$, and the powerless animals were rated to be more powerless than the powerless people, $F(1,30)=37.00, p<.001$. The valence did not differ between the conditions $(F \mathrm{~s}<1)$.

In the experiment, all the words were presented in black, 96-point (Unicode: lu9ed1\u4f53\u000dlu000a) (equal width of every line) font on a white background in the center of the screen.

\section{Procedures}

The experimental procedure was the same as Jiang et al. (2015a), with the following exceptions: Given that children respond more slowly than adults, each word was presented for 3 seconds (s) instead of $2 \mathrm{~s}$ (for adults). The experiment included two blocks of trials. Each block consisted of 5 practice trials and 64 formal trials. All the words appeared twice, once in each block. The response mappings (up or down keys for words representing powerful groups) were exchanged across the two blocks. 
In other words, each word appeared twice, once assigned to the up key and once to the down key. The block order was counterbalanced across participants.

Each trial started with a 500 ms cross presented in black, 96-point Courier New font on a white background in the center of the screen. A word then appeared for $3 \mathrm{~s}$ and participants were required to judge the power of the word by pressing (with one finger of their right hand, either index or middle finger) the up or down key on the keyboard as quickly and as accurately as possible. Before the experiments, the participants were instructed to lay a single finger in the middle between the two response keys. None of the participants moved their fingers out of the small area made of the two keys. Participants were informed that powerful individuals were those who could control others and powerless individuals were those who were controlled by others. After the experiment, the participants were asked whether they could recognize all the Chinese characters during the experiment. All the participants reported that they could.

The analyses were carried out separately for reaction times and error frequencies. First, a 2 (power) x 2 (response key) ANOVA was run for the childrens' data. Second, children and adults' data were combined, and a 2 (power) x 2 (response key) x 2 group (children vs. adults) ANOVA was carried out. ${ }^{2}$

\section{Results and Discussion}

\section{Reaction Times}

\footnotetext{
${ }^{2}$ We chose to present the analysis of only the children data first because only the children's data are original; the adult data have been reported before by Jiang et al. (2015a). Also note that we do not include the method factor animal vs. human target in the analysis in order to not complicate the Results section. Effects were always in the same direction for both, but in general somewhat stronger for human targets than animal targets. Further details can be obtained from the corresponding author.
} 
Following Zanolie et al. (2012) and Jiang et al. (2015a), wrong responses (errors) and response times more than two standard deviations faster or slower than the subject's condition mean were excluded. In total, $6.9 \%$ of trials were removed because of wrong responses, $0.9 \%$ of trials were removed because of no responses, and $4.9 \%$ were removed because of outlying reaction times. Reaction times of words representing powerful and powerless groups are represented in Table 1.

Consistent with our prediction, a 2 (power) x 2 (response key) ANOVA on average reaction time revealed that the interaction between power and response key was significant, $F(1,23)=11.11, p=.003, \eta_{\mathrm{p}}{ }^{2}=.33$. Further analyses indicated that children responded faster to words representing powerful groups with the up key, than the down key, $F(1,23)=12.06, p=.002, \eta_{\mathrm{p}}{ }^{2}=.34$, and faster to words representing powerless groups with the down key than the up key, $F(1,23)=8.62, p=.007, \eta_{\mathrm{p}}{ }^{2}$ $=.27$.

For comparison, data from 24 right-handed adults in our previous study (Jiang et al., 2015a) was also included for analysis. For the adults' data, $2.0 \%$ of trials were removed because of wrong responses, $0.4 \%$ of trials were removed because of no responses, and 5.4\% were removed because of outlying reaction times. Reaction times of words representing powerful and powerless groups are also represented in Table 1.

A 2 (group: children vs. adults) x 2 (power) x 2 (response key) ANOVA on average reaction time also revealed that the interaction between power and response key was significant, $F(1,46)=28.46, p<.001, \eta_{\mathrm{p}}{ }^{2}=.38$. Participants responded faster to words representing powerful groups with the up key than the down key, $F(1$, 
$47)=38.00, p<.001, \eta_{\mathrm{p}}{ }^{2}=.45$, and faster to words representing powerless groups with the down key than the up key, $F(1,47)=15.39, p<.001, \eta_{\mathrm{p}}^{2}=.25$. Most importantly, the three-way interaction between power, response key and group was not significant, $F(1,46)=.03, p=.873$, suggesting no evidence for an age difference in the power-space interactions. Other significant effects are described in the footnote. $^{3}$

\section{Error Frequencies}

Error frequencies (not including non-responses) of words representing powerful and powerless groups are represented in Table 2. A 2 (power) x 2 (response key) ANOVA on error frequencies revealed that only the interaction between power and response key was significant, $F(1,23)=16.26, p=.001, \eta_{\mathrm{p}}^{2}=.41$. Further analyses indicated that children made fewer errors to words representing powerful groups with the up key, $F(1,23)=10.36, p=.004, \eta_{\mathrm{p}}^{2}=.31$, and fewer errors to words representing powerless groups with the down key, but this difference was not significant, $F(1,23)=3.64, p=.069$.

3 The analysis revealed a number of additional significant effects. The main effect of group was significant, $F(1,46)=64.12, p<.001, \eta_{\mathrm{p}}^{2}=.58$, indicating that children gave slower responses than adults. We also found that participants responded faster to words representing powerful groups than words representing powerless groups, $F(1,46)=6.52, p=.014, \eta_{\mathrm{p}}^{2}=.12$, and pressing the down key was slower than pressing the up key, $F(1,46)=5.86, p=.019, \eta_{\mathrm{p}}^{2}=.11$. 
For comparison, data from the adults in our previous study (Jiang et al., 2015a) was also included for analysis. Error frequencies of words representing powerful and powerless groups are represented in Table 2. A 2 group (children vs. adults) x 2 power $\mathrm{x} 2$ response key ANOVA on error frequencies revealed that the interaction between power and response key was also significant, $F(1,46)=17.36, p<.001, \eta_{\mathrm{p}}{ }^{2}$ $=.27$, which suggested that there was no speed-accuracy trade-off that would undermine the main findings. Further analyses indicated that participants made fewer errors to words representing powerful groups with the up than the down key, $F(1,47)$ $=11.69, p=.001, \eta_{\mathrm{p}}^{2}=.20$, and fewer errors to words representing powerless groups with the down key than the up key, $F(1,47)=4.11, p=.048, \eta_{\mathrm{p}}^{2}=.08$.

The three-way interaction between power, response key and group was significant, $F(1,46)=4.86, p=.032, \eta_{\mathrm{p}}{ }^{2}=.10$. The interaction between power and response key was significant for children (see above), but not for adults, $F(1,23)=$ $2.56, p=.124$. However, this should be interpreted with caution because of the overall lower errors committed by adults. Other significant effects were described in the footnote. $^{4}$

The results of Experiment 1 indicated that children in Grade 4 showed the power-space interactions when they had to judge power explicitly, suggesting that children have developed the spatial representation of power even before they have

${ }^{4}$ The main effect of group was significant, $F(1,46)=12.92, p=.001, \eta_{\mathrm{p}}{ }^{2}=.22$, indicating that children made more errors than adults. 
formally learned power-space associations in school.

\section{Experiment 2}

In Experiment 1, we found that the interaction between vertical motor response and power during explicit power judgment was evident for children, suggesting that for children, explicit power evaluation of words activates the spatial representation of power (i.e., perceptual simulation of power-congruent space of that word). If the task-irrelevant motor movement was congruent with the activated image schema (up or down), responses would be facilitated. Our previous study (Jiang et al., 2015a) further revealed that for adults, even incidental semantic processing of power words (i.e., report whether the words represent people or animals) could automatically activate such perceptual simulation of power-congruent space.

The notion of perceptual simulation implies that the activation of modal content emerges relatively automatically during language comprehension, often without conscious awareness (Barsalou, 1999). More specifically, language comprehension of an object word is assumed to reactivate the neural pathways associated with perceiving that particular object (Barsalou, 1999; Martin, 2007). For example, the word bird and an image of a bird share common neural networks (Pulvermuller, 2001; Vandenberghe et al., 1996). Thus, just viewing object words (e.g., head, foot) activates an implicit perceptual simulation in the object's typical location (Šetic \& Domijan, 2007; Zwaan \& Yaxley, 2003). Viewing small or large numbers also activates a perceptual simulation of left-right space and automatically orients attention toward number-congruent location (Fischer, 2003; Fischer et al., 2003; Galfano, 
Rusconi, \& Umilta, 2006). Similarly, we showed that language comprehension of power words incidentally activates adults' perceptual simulation of that word, including the up-down image schema (Jiang et al., 2015a).

In Experiment 2, we test whether that process can also be observed in children. In contrast to Experiment 1, the interaction between vertical motor response and power was this time tested during incidental processing of power words (i.e., report whether the words represent people or animals). As in Jiang et al. (2015a), each word appeared twice, once assigned to the up key and once to the down key. The task, however, was not an explicit power evaluation, but rather a decision as to whether an animal or a human label is presented. If children spontaneously activate the spatial representation of power when reading words representing power, they should respond to words representing powerful groups faster with the up than the down cursor key and to words representing powerless groups faster with the down than the up cursor key. This is what Jiang et al. (2015a) found for adults, and we assumed the same would happen in children. Therefore, the interaction between power and space should not differ between the age groups. For comparison, the adults' data from Jiang et al. (2015a) were also included.

\section{Method}

\section{Participants}

Twenty-four right-handed volunteers from the same primary school as Experiment 1 (Grade 4) with normal or corrected-to-normal vision (12 males, 10.67 
years old, $S D=1.17$ ) participated in this experiment. The children were tested approximately 5 months before the end of the school year. Before the experiment, all the participants were asked which hand was their dominant, i.e., which hand they used to write or hold chopsticks. All the participants reported that they were right-handed. For comparison, data from twenty-four right-handed adults (9 males, 24.50 years old, $S D=3.59$ ) already presented in previous study (Jiang et al., 2015a) was also included.

\section{Materials}

The materials used in Experiment 2 were the same as Experiment 1.

\section{Procedures}

The experimental procedure was the same as Experiment 1 except that participants were required to judge whether the word represented a person or an animal by pressing the up or down key (with one finger of their right hand, either index or middle finger). Before the experiments, the participants were instructed to lay a single finger in the middle between the two response keys. The experiment included two blocks of trials. Each block consisted of 5 practice trials and 64 formal trials. All the words appeared twice, once in each block. The response mappings (up or down keys for people) were exchanged across the two blocks. In other words, each word appeared twice, once assigned to the up key and once to the down key. The block order was counterbalanced across participants. After the experiment, all the participants reported that they could recognize all the Chinese characters during the experiment.

The analyses were carried out separately for reaction times and error frequencies. 
First, a 2 (power) x 2 (response key) ANOVA was run with the childrens' data. Second, combining children and adults' data, a 2 (power) x 2 (response key) x 2 group (children vs. adults) ANOVA was carried out.

\section{Results and Discussion}

\section{Reaction Times}

In total, $3.2 \%$ of trials were removed because of wrong responses, $0.3 \%$ of trials were removed because of no responses and $5.0 \%$ were removed because of outlying reaction times. Reaction times of words representing powerful and powerless groups are represented in Table 3.

A 2 (power) x 2 (response key) ANOVA on reaction time showed that the key interaction of power $\mathrm{x}$ response key was not significant, $F(1,23)=.16, p=.692$.

For comparison, data from twenty-four right-handed adults in our previous study (Jiang et al., 2015a) was also included for analysis. For the adults' data, 1.9\% of trials were removed because of wrong responses, $0.4 \%$ of trials were removed because of no responses, and $4.3 \%$ were removed because of outlying reaction times. Reaction times of words representing powerful and powerless groups are also represented in Table 3.

A 2 group (children vs. adults) x 2 power x 2 response key ANOVA on reaction time revealed that the three-way interaction between power, response key and group was significant, $F(1,46)=5.21, p=.027, \eta_{\mathrm{p}}^{2}=.10$. Further analyses indicated that the interaction between power and response key was significant for adults, $F(1,23)=$ $18.68, p<.001, \eta_{\mathrm{p}}^{2}=.45$, but not for children, as seen above. Other significant effects 
are described in the footnote. ${ }^{5}$

\section{Error Frequencies}

Error frequencies (not including non-responses) for words representing powerful and powerless groups are represented in Table 4. A 2 (power) x 2 (response key) ANOVA on error frequencies showed no effects of interests. Other significant effects were described in the footnote. ${ }^{6}$

For comparison, data from adults in our previous study (Jiang et al., 2015a) was also included for analysis. Error frequencies of words representing powerful and powerless groups are also represented in Table 4. A 2 (group: children vs. adults) x 2 (power) x 2 (response key) ANOVA on error frequencies showed no effects of interests. Other significant effects were described in the footnote ${ }^{7}$.

5 The analysis revealed several additional significant effects. The main effect of group was significant, $F(1,46)=77.47, p<.001, \eta_{\mathrm{p}}{ }^{2}=.63$, indicating that children gave slower responses than adults. We also found that judgments of words representing powerless groups were slower than judgments of words representing powerful groups, $F(1,46)=6.31, p=.016, \eta_{\mathrm{p}}^{2}=.12$.

${ }^{6}$ Children made fewer errors for words representing powerful groups than words representing powerless groups, $F(1,23)=5.69, p=.026, \eta_{\mathrm{p}}^{2}=.20$.

7 The analysis revealed a number of significant effects. The main effect of group was significant, $F(1,46)=8.16, p=.006, \eta_{\mathrm{p}}{ }^{2}=.15$, indicating that children made more errors than adults. Participants made more errors on judgments of words 
The results of Experiment 2 showed that when the power concept was not explicitly processed, the power-space interaction disappeared for children, and children and adults differed significantly in the interference space exerts on process.

\section{General Discussion}

The current results demonstrate that when the power concept is explicitly evaluated, children's power judgments are affected by task-irrelevant vertical spatial information. Responses for power words are faster and more accurate when vertical motor movements are congruent with the activated image schema (up or down) of the words. The interaction between vertical motor responses and power appeared for both children and adults on reaction times, but only for children on errors (presumably because of the overall lower error rate in adults). The emergence of a significant effect in children is noteworthy because it confirms that children have developed the spatial representation of power even before they have formally learned power-space associations in school.

However, when the task does not explicitly require a power judgment, the interaction between power and response key disappears in children, although the comparison with the previous data using the exact same paradigm shows that adults do show this effect. This difference should be considered on the background of the literature that shows that children do interpret nonverbal size cues as social

representing powerless groups than words representing powerful groups, $F(1,46)=$ $10.38, p=.002, \eta_{\mathrm{p}}^{2}=.18$. 
dominance early on. We argue that the null results might be due to the following reasons: 1) (At least some) children did not activate the power concept at all in absence of the explicit task requirement, and/or 2) (some) processed the power concept incidentally, but did not activate the related up-down image schema automatically.

The current findings are comparable to previous results on the spatial representation of other magnitudes such as number. Numbers were shown to be represented as a horizontal number line: Large numbers are responded to faster with a right response key, whereas small numbers are responded to faster with a left response key (i.e., spatial-numerical association of response codes effect, SNARC effect, Dehaene et al., 1990,1993; Hubbard et al., 2005). Although even 7-year-old children exhibited such SNARC effect during explicit magnitude judgment (Van Galen \& Reitsma, 2008), the SNARC effect did not appear until 9 years of age when the numerical magnitude was not explicitly processed (e.g., parity judgment in Berch et al. (1999) or grey box detection in Van Galen and Reitsma (2008)). Based on their findings, Van Galen and Reitsma inferred that children did not have automatic access to the spatial representation of numbers until 9 years old. (Alternatively, it seems possible that the children did not process magnitude spontaneously.) Similarly, we argued that children of Grade 4 did not have automatic access to the spatial representation of power.

There are a number of possible explanations for the null results in children in Experiment 2 that we believe are not likely: 1) Were the semantic category judgments 
too difficult for children? No - in fact, children responded faster and with fewer errors when making semantic category judgments than power judgments, as a comparison of Study 1 and Study 2 shows; 2) Are children too inferior in their language comprehension? No - all the children reported that they could recognize all the Chinese words after the experiments and their response accuracy was higher than 0.9 ; 3) Did children not have the proper power concept? No - the same population performed well in Experiment 1. Furthermore, eye-movement studies (Mascaro \& Csibra, 2012; Thomsen et al., 2011) showed that even infants were sensitive to the power of two agents; 4) Are children's spatial representations of power too different from that of adults? Again, the results from both Experiment 1 and Brey and Shutts (2015) showed that children had developed the same relation between power and space as adults (powerful $=$ up, powerless $=$ down). Instead, the null result seems to be related to the fact that children do not automatically activate the power concept or its related spatial representation. Besides, one should be cautious not to overinterpret this null result, because it might be due to the relatively small sample size.

The results of the explicit power judgment task demonstrate that children in Grade 4 have developed a spatial representation of power. However, unfortunately, the design of the current study did not provide an opportunity to look at the developmental progress of the spatial representation of power. Because younger children were not included, we were not able to answer at what age the spatial representation of power arises. Future studies could use auditory materials or pictures to examine the spatial representation of power effect in younger children. However, 
most studies on the spatial representation of power for adults (Chiao et al., 2009; Chiao, 2010; Giessner \& Schubert, 2007; Jiang et al., 2015ab; Mason, Magee, \& Fiske, 2014; Schubert, 2005; Zanolie et al., 2012) used visually presented words as materials. Thus, before testing children with auditory or pictorial materials, it is necessary to verify that similar effects could be shown with other materials.

More broadly, our results support the grounded cognition framework (e.g., Barsalou, 1999, 2008; Glenberg, 1997). The basic tenet of this framework is that human cognition is body based. That is, conceptual thinking often relies on simulations of perceptual symbols, which are schematized perceptual experiences including senses, proprioception, introspection, and motor programs. There is now increasing evidence that abstract concepts are also grounded in sensory-motor representations through metaphors (Conceptual Metaphor Theory, Gibbs, 1994;

Lakoff \& Johnson, 1980, 1999). For example, power mapped to verticality (Giessner \& Schubert, 2007; Schubert, 2005; our study), physical force (Schubert, 2004) and size (Schubert, Waldzus, \& Giessner, 2009), social proximity mapped to temperature (Ijzerman\& Semin, 2009), social distance mapped to spatial distance (Parkinson \& Wheatley, 2013).

\section{Acknowledgments}

This research was supported by Projects Planning in Shanghai Philosophy and Social Sciences Research (2012JJY001) and the research fund of the School of Social Development and Public Policy at Fudan University. We thank Nora Grace Uhrich for proof-reading the manuscript. 


\section{References}

Barsalou, L. W. (1999). Perceptual symbol systems. Behavioral and Brain Sciences, 22, 577-609.

Barsalou, L. W. (2008). Cognitive and neural contributions to understanding the conceptual system. Current Directions in Psychological Science, 17, 91-95.

Berch, D. B., Foley, E. J., Hill, R. J., \& Ryan, P. M. D. (1999). Extracting parity and magnitude from Arabic numerals: Developmental changes in number processing and mental representation. Journal of Experimental Child Psychology, 74, 286-308.

Brey E., \& Shutts, K. (2015). Children use nonverbal cues to make inferences about social power. Child Development, 86, 276-286.

Boot, I., \& Pecher, D. (2011). Representation of categories: Metaphorical use of the container schema. Experimental Psychology, 58, 162-170.

Brauer, M., \& Bourhis, R. Y. (2006). Social power. European Journal of Social Psychology, 36, 601-616.

Casasanto, D. (2014). Experiential origins of mental metaphors: Language, culture, and the body. In M. Landau, M. D. Robinson, \& B. P. Meier (Eds.), The power of metaphor: Examining its influence on social life (pp. 249-268). Washington, DC: American Psychological Association.

Charafeddine, R., Mercier, H., Clément, F., Kaufmann, L., Berchtold, A., Reboul, A., \& Van der Henst, J-B (2015): How preschoolers use cues of dominance to make sense of their social environment. Journal of Cognition and Development, 
$16, .587-607$

Chiao, J. Y. (2010). Neural basis of social status hierarchy across species. Current Opinion in Neurobiology, 20, 803-809.

Chiao, J. Y., Harada, T., Oby, E. R., Li, Z., Parrish, T., \& Bridge, D. J. (2009). Neural representations of social status hierarchy in human inferior parietal cortex. Neuropsychologia, 47, 354-363.

Dahl, C. D., \& Adachi, I. (2013). Conceptual metaphorical mapping in chimpanzees (Pan troglodytes). eLife, 2013, 1-7.

Dehaene, S., Bossini, S., \& Giraux, P. (1993). The mental representation of parity and number magnitude. Journal of Experimental Psychology: General, 122, 371-396.

Dehaene, S., Dupoux, E., \& Mehler, J. (1990). Is numerical comparison digital? Analogical and symbolic effects in two-digit number comparison. Journal of Experimental Psychology: Human Perception and Performance, 16, 626-641.

Dienes, Z., \& Perner, J. (1999). A theory of implicit and explicit knowledge. Behavioral and Brain Sciences, 22, 735-808.

Fischer, M. H. (2003). Spatial representations in number processing: Evidence from a pointing task. Visual Cognition, 10, 493-508.

Fischer, M. H., Castel, A. D., Dodd, M. D., \& Pratt, J. (2003). Perceiving numbers causes spatial shifts of attention. Nature Neuroscience, 6, 555-556.

Galfano, G., Rusconi, E., \& Umilta, C. (2006). Number magnitude orients attention, but not against ones will. Psychonomic Bulletin \& Review, 13, 869-874.

Galinsky, A. D., Gruenfeld, D., \& Magee, J. C. (2003). From power to action. Journal 
of Personality and Social Psychology, 85, 453-466.

Giessner, S. R., \& Schubert, T. W. (2007). High in the hierarchy: How vertical location and judgments of leaders' power are interrelated. Organizational Behavior and Human Decision Processes, 104, 30-44.

Glenberg, A. M. (1997). What memory is for. Behavioral and Brain Sciences, 20, $1-55$.

Gibbs, R. W. (1994). The poetics of mind: Figurative thought, language, and understanding. New York, NY: Cambridge University Press.

Hommel, B., Musseler, J., Aschersleben, G., \& Prinz, W. (2001). The theory of event coding (TEC): A framework for perception and action planning. Behavioral and Brain Sciences, 24, 849-937.

Hubbard, E. M., Piazza, M., Pinel, P., \& Dehaene, S. (2005). Interactions between number and space in parietal cortex. Nature Reviews Neuroscience, 6, 435-448.

Ijzerman, H., \& Semin, G. R. (2009). The thermometer of social relations. Mapping social proximity on temperature. Psychological Science, 20, 1214-1220.

Jiang, T., Sun, L., \& Zhu, L. (2015a). The influence of vertical motor responses on explicit and incidental processing of power words. Consciousness and Cognition, $34,33-42$.

Jiang, T. \& \& Zhu, L. (2015b). Is power-space a continuum? Distance effect during power judgments. Consciousness and Cognition, 37, 8-15.

Keltner, D., Gruenfeld, D., \& Anderson, C. P. (2003). Power, approach, and inhibition. Psychological Review, 110, 265-284. 
Kirsh, D. (1991) When is information explicitly represented? In: Information, thought, and content, ed. P. Hanson. UBC Press.

Lakoff, G. (1987). Women, fire, and dangerous things. Chicago: University of Chicago Press.

Lakoff, G., \& Johnson, M. (1980). Metaphors we live by. Chicago: University of Chicago Press.

Lakoff, G., \& Johnson, M. (1999). Philosophy in the flesh. New York, NY: Basic Books.

Martin, A. (2007). The representation of object concepts in the brain. Annual Review of Psychology, 58, 25-45.

Mascaro, O., \& and Csibra, G. (2012). Representation of stable social dominance relations by human infants. PNAS, 109, 6862-6867.

Mason, M., Magee, J. C., \& Fiske, S. T. (2014). Neural substrates of social status inference: roles of medial prefrontal cortex and superior temporal sulcus. Journal of Cognitive Neuroscience, 26, 1131-1140.

Meier, B. P., \& Dionne, S. G. (2009). Downright sexy: Verticality, implicit power, and perceived physical attractiveness. Social Cognition, 27, 883-892.

Meier, B. P., \& Robinson, M. D. (2004). Why the sunny side is up: Associations between affect and vertical position. Psychological Science, 15, 243-247.

Neumann, R., \& Strack, F. (2000). Approach and avoidance: The influence of proprioceptive and extereoceptive cues on encoding of affective information. Journal of Personality and Social Psychology, 79, 39-48. 
Parkinson, C., \& Wheatley, T. (2013). Old cortex, new contexts: Re-purposing spatial perception for social cognition. Frontiers in Human Neuroscience, 7, 645.

Pulvermuller, F. (2001). Brain reflections of words and their meaning. Trends in Cognitive Sciences, 5, 517-524.

Schubert, T. W. (2004). The power in your hand: Gender differences in bodily feedback from making a fist. Personality and Social Psychology Bulletin, 30, 757-769.

Schubert, T. W. (2005). Your highness: Vertical positions as perceptual symbols of power. Journal of Personality and Social Psychology, 89, 1-21.

Schubert, T. W., Waldzus, S., \& Giessner, S. R. (2009). Control over the association of power and size. Social Cognition, 27, 1-19.

Schwartz, B., Tesser, A., \& Powell, E. (1982). Dominance cues in nonverbal behavior. Social Psychology Quarterly, 45(2), 114-120.

Šetic, M., \& Domijan, D. (2007). The influence of vertical spatial orientation on property verification. Language and Cognitive Processes, 22, 297-312.

Smith, E. R. (1984). Model of social inference processes. Psychological Review, 91, $392-413$

Squire, L. R. (1992) Memory and the hippocampus: A synthesis from findings with rats, monkeys, and humans. Psychological Review, 99, 195-231.

Suitner, C., \& Schubert, T. W. (in press). Grounding social cognition in space. In Hubbard, T. (Ed.), Spatial biases in perception and cognition. Cambridge University Press. 
Thomsen, L., \& Carey, S. (2013). Core cognition of social relations. In M. R. Banaji \& S. Gelman (Eds.), Navigating the social world. What infants, children, and other species can teach us (pp. 17-22). New York: Oxford University Press.

Thomsen, L., Frankenhuis, W. E., Ingold-Smith, M., \& Carey, S. (2011). Big and mighty: Preverbal infants mentally represent social dominance. Science, 331, 477-480.

Vandenberghe, R., Price, C., Wise, R., Josephs, O., \& Frackowiak, R. S. J. (1996). Functional anatomy of a common semantic system for words and pictures. Nature, $383,254-256$.

van Galen, M. S., \& Reitsma, P. (2008). Developing access to number magnitude: A study of the SNARC effect in 7- to 9-year-olds. Journal of Experimental Child Psychology, 101, 99-113.

von Hecker, U., Klauer, K. C., \& Sankaran, S. (2013). Embodiment of social status: Verticality effects in multilevel rank-orders. Social Cognition, 31(3), 374-389.

Wu, N., Yang, Y., Liu, J. (2007). Cognitive Analysis of Metaphor Domains of Spatial Dimensionality Words 'high/low' in Children's Literary Language. Journal of Jimei University, 8, 11-15. (Chinese)

Zanolie, K., Dantzig, S., Boot, I., Wijnen, J., Schubert, T. W., Giessner, S. R., \& Pecher, D. (2012).

Mighty metaphors: behavioral and ERP evidence that power shifts attention on a vertical dimension. Brain \& Cognition, 78, 50-58.

Zorzi, M., Priftis, K., and Umilta, C. (2002). Brain damage: neglect disrupts the 
mental number line. Nature, 417, 138-139.

Zwaan, R. A., \& Yaxley, R. H. (2003). Spatial iconicity affects semantic relatedness judgments. Psychonomic Bulletin \& Review, 10, 954-958. 
Tables

Table 1. Mean Reaction Times (in ms) of Power Words for Children and Adults (Experiment 1).

\begin{tabular}{|c|c|c|c|c|c|c|c|c|c|}
\hline \multicolumn{5}{|c|}{ Children } & \multicolumn{5}{|c|}{ Adults (Jiang et al., 2015a) } \\
\hline & \multicolumn{4}{|c|}{ Response Key } & & \multicolumn{4}{|c|}{ Response Key } \\
\hline & \multicolumn{2}{|c|}{ Up } & \multicolumn{2}{|c|}{ Down } & & \multicolumn{2}{|c|}{$\mathrm{Up}$} & \multicolumn{2}{|c|}{ Down } \\
\hline & $M$ & $S D$ & $M$ & $S D$ & & $M$ & $S D$ & $M$ & $S D$ \\
\hline Powerful & 1009 & 165 & 1122 & 180 & Powerful & 704 & 69 & 830 & 145 \\
\hline Powerless & 1132 & 197 & 1037 & 154 & Powerless & 830 & 148 & 760 & 87 \\
\hline
\end{tabular}

Table 2. Mean Error Frequencies of Power Words for Children and Adults (Experiment 1).

\begin{tabular}{|c|c|c|c|c|c|c|c|c|c|}
\hline \multicolumn{5}{|c|}{ Children } & \multicolumn{5}{|c|}{ Adults (Jiang et al., 2015a) } \\
\hline & \multicolumn{4}{|c|}{ Response Key } & & \multicolumn{4}{|c|}{ Response Key } \\
\hline & \multicolumn{2}{|c|}{$\mathrm{Up}$} & \multicolumn{2}{|c|}{ Down } & & \multicolumn{2}{|c|}{$\mathrm{Up}$} & \multicolumn{2}{|c|}{ Down } \\
\hline & $M$ & $S D$ & $M$ & $S D$ & & $M$ & $S D$ & $M$ & $S D$ \\
\hline Powerful & 2.33 & 3.17 & 3.29 & 3.64 & Powerful & 0.42 & 1.64 & 0.62 & $\overline{1.86}$ \\
\hline Powerless & 1.96 & 1.88 & 1.29 & 1.76 & Powerless & 0.88 & 2.03 & 0.58 & 1.44 \\
\hline
\end{tabular}

Table 3. Mean Reaction Times (in ms) of Power Words for Children and Adults (Experiment 2).

\begin{tabular}{|c|c|c|c|c|c|c|c|c|c|}
\hline \multicolumn{5}{|c|}{ Children } & \multicolumn{5}{|c|}{ Adults (Jiang et al., 2015a) } \\
\hline & \multicolumn{4}{|c|}{ Response Key } & & \multicolumn{4}{|c|}{ Response Key } \\
\hline & \multicolumn{2}{|c|}{$\mathrm{Up}$} & \multicolumn{2}{|c|}{ Down } & & \multicolumn{2}{|c|}{ Up } & \multicolumn{2}{|c|}{ Down } \\
\hline & $M$ & $S D$ & $M$ & $S D$ & & $M$ & $S D$ & $M$ & $S D$ \\
\hline Powerful & 879 & 133 & 873 & 134 & Powerful & 596 & 64 & 631 & 76 \\
\hline Powerless & 889 & 133 & 890 & 137 & Powerless & 630 & 78 & 625 & 71 \\
\hline
\end{tabular}

Table 4. Mean Error Frequencies of Power Words for Children and Adults (Experiment 2). 


\begin{tabular}{|c|c|c|c|c|c|c|c|c|c|}
\hline & \multicolumn{4}{|c|}{ Response Key } & & \multicolumn{4}{|c|}{ Response Key } \\
\hline & \multicolumn{2}{|c|}{$\mathrm{Up}$} & \multicolumn{2}{|c|}{ Down } & & \multicolumn{2}{|c|}{$\mathrm{Up}$} & \multicolumn{2}{|c|}{ Down } \\
\hline & $M$ & $S D$ & $M$ & $S D$ & & $M$ & $S D$ & $M$ & $S D$ \\
\hline Powerful & 0.83 & 1.09 & 0.71 & 0.81 & & 0.33 & 0.64 & 0.58 & 0.83 \\
\hline Powerless & 1.17 & 0.92 & 1.46 & 1.22 & Powerless & 0.79 & 1.02 & 0.71 & 0.75 \\
\hline
\end{tabular}


Appendix

Words Represent People Used in the Experiments

\begin{tabular}{llrr}
\hline Word & In English & $\begin{array}{c}\text { Valence } \\
\text { Rating }\end{array}$ & $\begin{array}{c}\text { Power } \\
\text { Rating }\end{array}$ \\
\hline 霸主 & Overlord & 4.75 & 6.75 \\
君主 & Sovereign & 5.42 & 6.33 \\
首领 & Leader & 4.92 & 5.50 \\
校长 & Principal & 4.33 & 4.17 \\
主人 & Host & 3.50 & 4.25 \\
主任 & Director & 3.25 & 3.33 \\
总理 & Premier & 4.75 & 5.42 \\
总统 & President & 4.92 & 6.17 \\
官员 & Officer & 2.92 & 4.50 \\
国王 & King & 4.50 & 5.83 \\
将军 & General & 5.17 & 5.42 \\
教练 & Coach & 4.08 & 3.17 \\
经理 & Manager & 3.92 & 3.75 \\
老板 & Boss & 3.67 & 4.58 \\
统治者 & Governor & 3.42 & 6.50 \\
政治家 & Politician & 2.83 & 4.33 \\
\hline & & &
\end{tabular}

\begin{tabular}{llcr}
\hline Word & \multicolumn{1}{c}{ In English } & $\begin{array}{c}\text { Valence } \\
\text { Rating }\end{array}$ & $\begin{array}{c}\text { Power } \\
\text { Rating }\end{array}$ \\
\hline 孩子 & Child & 5.92 & 1.92 \\
农夫 & Plowman & 4.58 & 3.33 \\
农民 & Farmer & 4.33 & 3.33 \\
仆人 & Servant & 3.25 & 2.08 \\
实习生 & Intern & 4.08 & 2.50 \\
士兵 & Soldier & 4.50 & 4.08 \\
水手 & Sailor & 5.00 & 3.83 \\
学生 & Student & 5.00 & 3.00 \\
保姆 & Nurserymaid & 3.67 & 2.58 \\
病人 & Sick person & 2.83 & 1.75 \\
孤儿 & Orphan & 3.25 & 1.67 \\
奴隶 & Slave & 2.17 & 1.75 \\
随从 & Attendant & 3.08 & 2.42 \\
学徒 & Apprentice & 3.67 & 2.58 \\
Ү头 & Bonne & 4.83 & 2.00 \\
肾儿 & Baby & 6.17 & 1.58 \\
\hline & & &
\end{tabular}


Words Represent Animals Used in the Experiments

\begin{tabular}{llrr}
\hline Word & \multicolumn{1}{c}{ In English } & $\begin{array}{c}\text { Valence } \\
\text { Rating }\end{array}$ & $\begin{array}{c}\text { Power } \\
\text { Rating }\end{array}$ \\
\hline 狮子 & Lion & 5.33 & 6.42 \\
非洲狮 & Africa lion & 5.08 & 6.50 \\
猎豹 & Cheetah & 5.08 & 5.67 \\
老虎 & Tiger & 4.92 & 6.25 \\
东北虎 & Northeast Tiger & 5.08 & 6.42 \\
黑熊 & Black bear & 3.83 & 5.92 \\
野熊 & Wild bear & 3.92 & 6.08 \\
大象 & Elephant & 5.83 & 5.67 \\
藏獒 & Tibetan Mastiff & 3.92 & 5.50 \\
蟒蛇 & Boa & 2.50 & 5.33 \\
巨蟒 & Python & 2.42 & 5.83 \\
大白鲨 & Great white shark & 4.17 & 5.83 \\
鲨鱼 & Shark & 4.00 & 5.42 \\
巨鲸 & Gigantic whale & 5.50 & 5.08 \\
蓝鲸 & Blue whale & 5.67 & 4.75 \\
鳄鱼 & Crocodile & 3.67 & 5.83 \\
\hline
\end{tabular}

\begin{tabular}{llrr}
\hline Word & \multicolumn{1}{c}{ In English } & $\begin{array}{c}\text { Valence } \\
\text { Rating }\end{array}$ & $\begin{array}{c}\text { Power } \\
\text { Rating }\end{array}$ \\
\hline 小鸡 & Chick & 4.75 & 1.25 \\
鸭子 & Duck & 4.50 & 1.50 \\
兔子 & Rabbit & 5.58 & 1.42 \\
小猫 & Kitten & 5.58 & 1.58 \\
吉娃娃 & Chihuahua & 4.83 & 1.42 \\
金鱼 & Goldfish & 4.75 & 1.08 \\
蜗牛 & Snail & 4.00 & 1.00 \\
蝀蚪 & Tadpole & 4.00 & 1.00 \\
松鼠 & Squirrel & 5.92 & 1.58 \\
小白鼠 & Mice & 4.75 & 1.17 \\
蜻蜓 & Dragonfly & 4.08 & 1.08 \\
蝴蝶 & Butterfly & 4.50 & 1.08 \\
蚂蚁 & Ant & 3.50 & 1.33 \\
毛毛虫 & Caterpillar & 1.58 & 1.33 \\
虾蚂 & Earthworm & 2.50 & 1.25 \\
麻雀 & Sparrow & 3.83 & 1.50 \\
\hline
\end{tabular}

